\title{
EDITORIAL
}

\section{The IJGO welcomes a new editor}

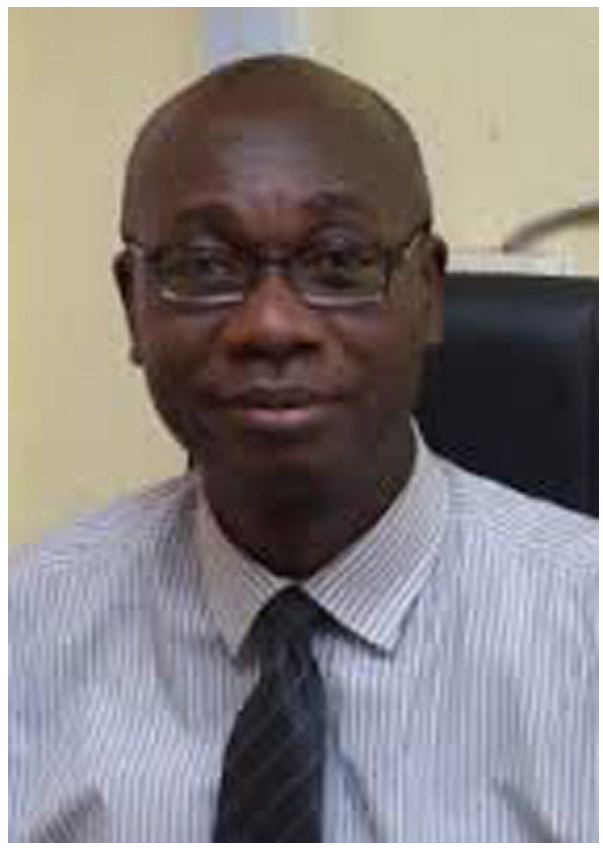

Richard Adanu, MBChB, MPH, FGCS, FWACS Dean, School of Public Health University of Ghana, Legon, Ghana

It is a privilege to take this opportunity to introduce the new Editor of the International Journal of Gynecology and Obstetrics (IJGO), Richard M.K. Adanu, MBChB, MPH, and a Fellow of the Ghana College of Surgeons and Fellow of the West African College of Surgeons. Doctor Adanu assumed the editorship of the IJGO upon the approval of the FIGO Executive Board in late 2014. He is Dean of the School of Public Health at the University of Ghana; Professor of Population, Family, and Reproductive Health; and a consultant in obstetrics and gynecology at the University of Ghana. As Editor of the Contemporary Issues in Women's Health section and member of the Editorial Board, Doctor Adanu has been an engaged member of the IJGO editorial team and has helped develop a future vision to carry IJGO into a successful future. Doctor Adanu is an accomplished clinician, public health educator, and academic administrator with special interest and expertise in issues of women's health in low-resource countries.

When I assumed the Editorship of the IJGO in January 2007 it was for an initial six-year appointment, with the intention that the editorship would have a definite time limit. When the six years expired at the end of 2012, given the timing of the triennial FIGO Congress in Rome, the President and Chief Executive of FIGO asked me to extend for a short period of time, which I did, so that the transition to a new editor could occur in a non-Congress year. This led to the successful identification of Doctor Adanu following interview of a number of extremely highly qualified candidates. Doctor Adanu will be present to participate broadly in the FIGO World Congress in Vancouver, Canada, in October 2015.

In the years since I assumed the editorship of the IJGO we have successfully completed the move to electronic submission of manuscripts and established a full-time editorial office in London. We have benefitted from the extraordinary leadership of an excellent managing editor, Clare Addington, and a number of dedicated team members, including Pete Chapman and our current deputy managing editor, Abi Cantor, and editorial assistant, Helen Metherell. On a geographic basis, the printed edition of the IJGO has become less important as major access to the Journal has been through electronic media. The number of electronic hits has increased steadily-to 538000 in 2013 (Fig. 1). Our audience can now follow IJGO on Twitter (@IJGOLive) and an iPad App is also available (http://www.ijgo.org/content/mobileaccessinstructions).

There has also been a satisfying, gratifying increase in the impact factor and other editorial metrics measures such as a decrease in publication time and increased author satisfaction, which ranks well above average for overall satisfaction on Elsevier's author feedback program. The global origin of our submissions (Fig. 2) and reviewers (Fig. 3) satisfyingly reflect the breadth of FIGO. We continue to publish the FIGO cancer staging [1], and the FIGO PALM-COEIN classification of abnormal bleeding [2] has been a top download (3000 in 2013) and is widely accepted by gynecologists.

The IJGO was first published in 1963 as the official journal of the International Federation of Gynecology and Obstetrics (FIGO). The first editor of the Journal was Professor Giuseppe Tesauro of Naples. The second editor was Doctor Harold Kaminetzky who served from 1968-1985, followed by Doctor John Sciarra who served from 1985-2007, and then myself, making Doctor Adanu only the fifth editor in the IJGO's 50 years of existence. It is exciting for me that for the first time we have an editor representing lower-resourced regions of the world.

During my years, it has been my privilege to work closely with the London office, managing editor Clare Addington, and especially the FIGO officers, the London Secretariat including chief executive, Professor Hamid Rushwan, administrative director Bryan Thomas, Marie-Christine Szatybelko, as well as our colleagues at Elsevier Science, most recently publisher Greyling Peoples.

During my tenure, the Journal has been particularly interested in issues of social access, capacity, reproductive justice, and has published 


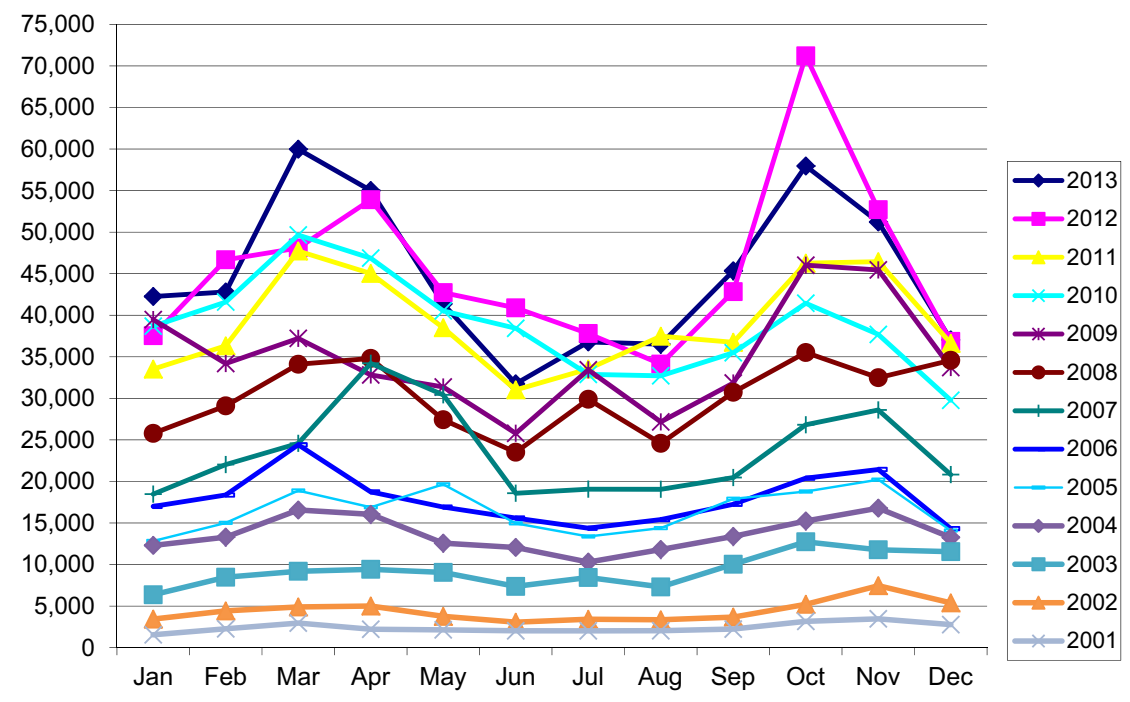

Fig. 1. IJGO full text article downloads (2001-2013) from ScienceDirect (Elsevier).

\section{North America $\square$ Africa \\ Europe \\ - Latin America \\ Asia/Australia \\ Middle east}

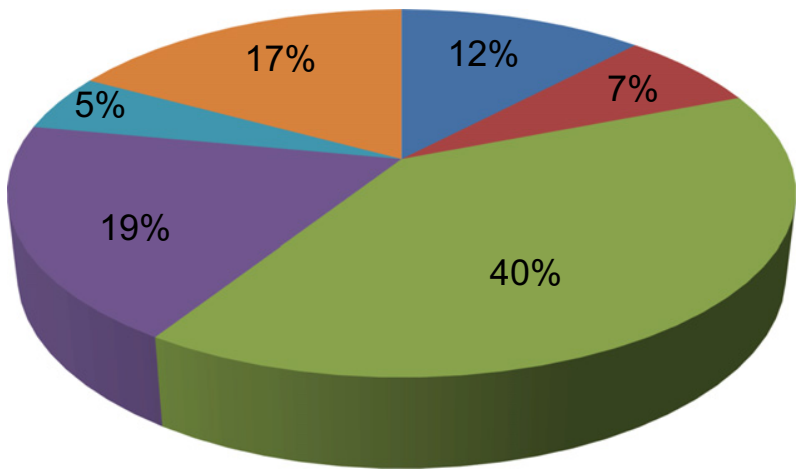

Fig. 2. Origin of submitted papers, 2013.
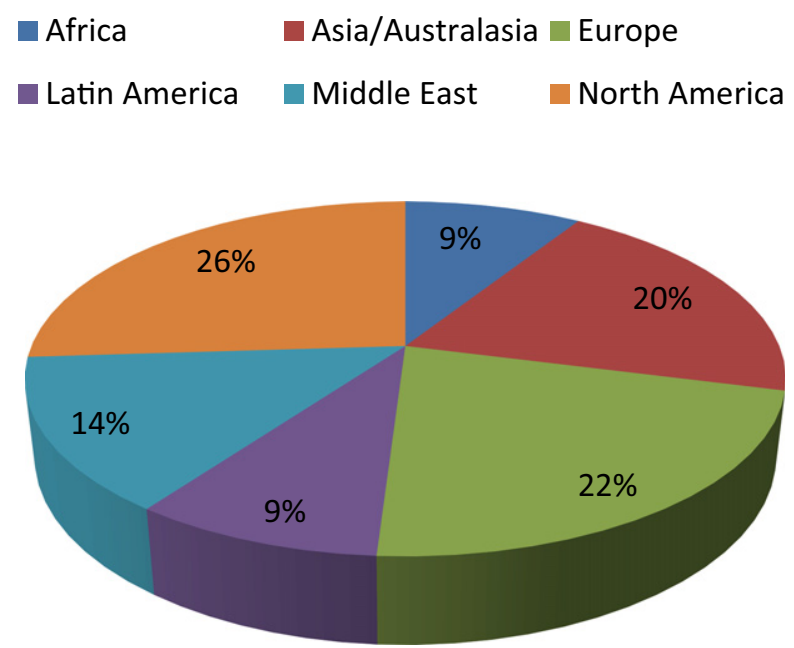

Fig. 3. Geographical location of IJGO peer reviewers, 2013-2014. important works on abortion, misoprostol, and community-based services. We have had an excellent series on averting maternal death and disability edited by Doctor Judith Fortney [3], and are now entertaining a new, exciting collaborative with Evidence for Action, a DFID-funded program that contributes to global efforts toward improving accountability in maternal and neonatal health in six African countries [4]. The first articles were published in the October 2014 issue and are free to download (http://www.ijgo.org/).

In the future, IJGO will continue to have a broad international appeal using electronic media, social media, and others to connect with its constituents, our colleague obstetrician/gynecologists, and those scientists and policy advisors who are committed to women's health.

We have an outstanding new editor in Richard Adanu and I trust that under his editorship the IJGO, in service to FIGO and as a source of scientific knowledge and educational dissemination to the members of FIGO, will be a beacon for the values represented by our international federation. I am grateful to FIGO for the privilege of serving as the editor of the IJGO, to all of our authors, and to so many others who have made this a great learning experience and opportunity for personal growth that I will always cherish as one of the highlight opportunities of my professional career. I look forward to continuing to loyally serve FIGO as Editor Emeritus.

\section{References}

[1] Denny L, editor. FIGO Cancer Report 2012, 119(Suppl. 2). Int J Gynecol Obstet; 2012 p. S89-S159.

[2] Munro MG, Critchley HO, Broder MS, Fraser IS, FIGO Working Group on Menstrual Disorders. FIGO classification system (PALM-COEIN) for causes of abnormal uterine bleeding in nongravid women of reproductive age. Int J Gynecol Obstet 2011;113 (1):3-13.

[3] Fortney JA Sciarra JJ. Editor's final comment. Int J Gynecol Obstet 2011:115(3):298-9.

[4] Fortney JA. Looking beyond the Millennium Development Goal deadline for women and newborns: Evidence is needed for action on implementation of quality care. Int J Gynecol Obstet 2014;127(1):94-5.
Timothy R.B. Johnson Editor Emeritus, IJGO University of Michigan, Ann Arbor, USA E-mail address: trbj@umich.edu. 